\title{
FAMÍLIA: ÉTICA E ESTÉTICA DO VIVER NO MUNDO
}

\author{
FAMILY: ETHICS AND AESTHETIC OF LIVING IN THE WORLD \\ FAMILIA: ETICA Y ESTETICA DE LO VIVIR EN EL MUNDO
}

Maria Socorro Pereira Rodrigues* Elísio Holanda Guedes Sobrinho** Raimunda Magalhães da Silva***

RESUMO: 0 presente trabalho enfatiza os aspectos da conduta ética e moral que permeiam o espaço social das famílias e de seus membros. Aborda questões e princípios necessários de serem trabalhados em família, tendo em vista um conviver saudável, melhorando o nível de satisfação pessoal, o que inclusive poderá contribuir para reduzir os eventos de violência própria e com os demais que compartilham o espaço "mundus vivendi" no ambiente familiar e social.

DESCRITORES: Família; Ética; Estética.

\section{INTRODUÇÃO}

0 atual contexto em que vive a sociedade, clama que se desenvolva trabalhos em prol da família e da cidadania. S ejam eles de qualquer natureza, desde que venham a contribuir para melhorar o nível de satisfação e de felicidade da sociedade.

Este trabalho busca revisitar conceitos e tipos de padrões éticos, mesmo tendo-se que considerar que ninguém consegue ficar indiferente aos próprios padrões, ao que pensa e acredita. A pessoa pensa e age segundo seus esquemas mentais. Irá julgar e avaliar fatos, sempre em consonância com os padrões construídos, mesmo que muitas vezes deturpados, conforme seja o ângulo pelo qual seja visto e a ideologia de quem avalia. Todas as pessoas, de alguma forma já se depararam ou se depararão com algum fato bom ou mau, que lhe chame a refletir sobre o mesmo.

Os objetivos ou metas de vida, devem estar baseados nos valores humanos. A própria escolha das estratégias para atingi-los envolve a necessidade de o indivíduo estar apto a assumir responsabilidades e dirigir seu próprio comportamento. Há necessidade de uma orientação clara, específica, criteriosa em relação às práticas de vida a serem adotadas, sendo importante destacar que um bom relacionamento, favorecerá 0 alcance desses objetivos.

Várias culturas e sociedades, influenciam nos padrões de conduta, assim como nos diferentes valores éticos, ao mesmo tempo em que, atualmente, diversos marcos conceituais vêem embasando reflexões éticas, frente as várias formas de injustiças sociais e dificuldades de sobrevivência. Haja visto o próprio quadro de violência que se delineia, desencadeado pelos avanços tecnológicos que vêm propiciando um assustador poder de intervenção sobre a vida, e também, suas decorrentes conseqüências para os indivíduos e para a sociedade, o que põe continuamente em cheque valores e formas de condutas, suscetibilizando ao desrespeito, códigos e compromissos éticos, (Boemer e Sampaio, 1997).

$\mathrm{Na}$ antigüidade, em especial na civilização grega, valor especial era centrado na concepção da harmonia, da serenidade, da medida, da simplicidade e da sobriedade. Tinha-se por lema reproduzir só o belo, na concepção de que esse une-se ao bom seguindo o princípio de que o ser verdadeiramente belo deve ser agradável não

\footnotetext{
* Professora Doutora do Departamento de Enfermagem da Universidade Federal do Ceará. Coordenadora do Grupo de Estudos e Pesquisa em Enfermagem Saúde e Quotidiano (GEPESQUES). Rua Gustavo Sampaio, 1413. Ap.603. São Gerardo. CEP. 60.455-001. Fortaleza-Ce. E-mail <socorro@ufc.br>

** Professor de Química. Licenciado pela Universidade Federal do Ceará. Av. Sargento Hermínio, 2755. BI L, Apto. 104. São Gerardo. Fortaleza-Ce. E-mail <elisiog@bol.com.br>

*** Professora Doutora do Departamento de Enfermagem da Universidade Federal do Ceará. Coordenadora do Grupo de Estudos da Saúde da Mulher e Cotidiano. Rua Rafael Tobias, 2079. CEP. 60853-680. Agua Fria. E-mail:<rmsilva@ ufc.br>
} 
somente para a vista, mas também ser bom em seu interior. Concepção essa tangenciada pela arte e pelos ideais de equilíbrio, da harmonia, da ordem, da moderação, a poiada no princípio de que todo trabalho ou lazer, movimentos ou cantos, quando realizados em conjunto transmitem uma bela harmonia. As características de belo consideradas mais importantes, eram a ordem, a simetria e os limites. J ankélévitch (1991), citando Plotino, refere que bem é superior ao belo e reina no mundo inteligível além das coisas excelentes.

A arte era considerada uma atividade essencialmente fortificadora do espírito, tendo por característica básica ser criadora, já que produz um tipo desejado de realidade, envolvendo a capacidade imaginativa para um fim que se tenha em vista, seja ele estético, político ou cultural. Inspirava-se na religião, no amor, na harmonia e em fatos da vida cotidiana, desenvolvida através do teatro, da religião, de danças, músicas, jogos ou de outras formas. As tribos associavam arte, dança e religião para reverenciar o Desconhecido, agradecendoIhe a abundância da caça, a fertilidade da terra e dos homens.

Cohen \& Ferraz (1995), afirmam que reflexões éticas sobre novos marcos contextuais referentes à condutas frente à situações-dilema, incidem sobre a formação do sujeito ético, e essa acontece no âmbito das relações humanas, na prática cotidiana.

Ao longo da história, entretanto, vemos relatos sobre fatos que envolvem forte dissonância a este contexto, o que provoca uma verdadeira deturpação do valor vida-arte-ética-estética.

\section{A ÉTICA EM FAMÍLIA}

Os "valores éticos" independem da contemporaneidade, contemplam a dignidade do homem, e originamse na carta magna dos direitos do cidadão. É importante pensar-se no compromisso ético que deve ter cada pessoa para com a qualidade das gerações, e com a melhoria das condições de vida da coletividade.

S egundo Nouwen (1997), existe uma verdadeira traição pela própria família aos seus próprios valores e da comunidade á qual ela está inserida, uma vez que cabe a esta transmitir valores éticos. Segundo Rodrigues; Guedes Sobinho; Silva (2000), a formação do cidadão, é uma árdua e complexa tarefa, que cabe, em primeira instância, essencialmente à família.

É a partir de uma concepção filosófica de homem, enquanto ser histórico, social, ser conscientemente transformador do mundo que o rodeia e no qual está inserido; do entendimento, da compreensão do que é bom e do que deve ser bem para todos, que o ser humano define o seu fazer. Será a partir de seu desenvolvimento no sentido de transformar sua própria natureza, para assumir riscos e para o enfrentamento de situações, muitas vezes, até adversas, com o fim de contribuir para o afastamento da dor, da miséria e da infelicidade, que o ser humano configurará a sua ética, parafraseando Lunardi (1994). A mesma autora, citando Gelain, destaca que a ciência que estuda os deveres de um grupo profissional refere-se à ética profissional, o que em analogia, nos leva a asseverar que a ética da família corresponde ao conjunto de princípios que devem nortear o grupo familiar no aprimoramento de suas relações interpessoais, sejam no seio familiar, individual ou coletivo, em sociedade.

A receptividade a qualquer solicitação, no quotidiano familiar, depende sempre da atitude mental e da forma como ela é transmitida, uma vez que, a emoção é fator fundamental em qualquer mensagem, seja ela transmitida com sutileza ou com severidade, daí dizer-se que os ensinamentos devem emergir do coração. A confiança e o respeito são fatores fundamentais em qualquer relação e, essa é muito sutilmente perceptível. Quando a pessoa percebe que uma mensagem ou admoestação é colocada egoisticamente, a tendência será sempre rejeitá-la.

Condutas éticas, estéticas e familiares, devem ser conduzidas baseando-se em princípios norteadores, a fim de resguardar a sua coerência. Rodrigues, Guedes Sobinho, Silva (2.000), apresentam esse conjunto de princípios, os quais vêem assim resumidos: desenvolver a arte do diálogo, com ênfase na afetividade; servir de apoio nos momentos de dificuldades; desenvolver a capacidade de fazer elogios, desenvolvendo a autoconfiança; ter flexibilidade quanto às crenças individuais e respeito à opinião e a percepção de cada um; ter flexibilidade quanto aos papéis e regras dentro da família; desenvolver a capacidade de escutar críticas, e estar aberto a substituir padrões culturais; desenvolver um padrão de comunicação harmoniosa, espontâneo, e respeito aos padrões do outro; respeitar sempre a independência do outro, relevando suas limitações; es timular a socialidade e desenvolver o espírito de solidariedade em família; orientar para um desenvolvimento das capacidades integrais, 
a responsabilidade ética e social nos atos e atitudes; orientar quanto aos meios de comunicação e de informação, de qualquer natureza, acessíveis ao seio familiar; fazer críticas, de modo sutil, mas sinceras, promovendo 0 auto aperfeiçoamento; observar o respeito aos sentimentos e pensamentos do outro; estar atento ao constante crescimento e aprendizagem do jovem, a fim de apoiá-lo; procurar ajuda de alguém com um bom grau de formação, para ajudar em eventos na família, considerados extraordinários, sejam doenças, hospitalizações, divórcio, desenlaces ou outros; estimular o enfrentamento das dificuldades, com serenidade e apoiados na fé; desenvolver o estímulo ao trabalho, sempre voltado para alguma profissão; respeitar sempre a liberdade do outro, a expressão de emoções e sentimentos. A esses, incluem-se necessariamente, a atitude de autodeterminação, que envolve a capacidade de pensar, refletir e filosofar; da dignidade e da liberdade.

A pessoa deve sentir-se descomprometida e apta a atender a própria vontade, exercendo seu poder sobre o sujeito moral. Q uanto maior for a consciência que uma pessoa tenha de si mesma e de seus sentimentos, maior será o controle que exercerá sobre sua conduta. 0 dever moral nos dita uma tarefa tão esgotante quanto inesgotável, o dever exige uma tensão e uma vontade infatigáveis, na medida de um esforço sempre recomeçado e sempre inacabado. Há entre o dever e o poder, uma desproporção que o querer procura loucamente compensar.

Certas mudanças nos padrões de vida forçam os grupos a elaboração e incorporação de novas regras de condutas, introduzindo assim mudanças em seus princípios e valores, de tal forma que essas possam vir a melhorar suas formas de vida. Collet; Rozendo, Palvelqueires (1995), destacam a necessidade de a ética tornar-se um exercício, saindo do âmbito das questões normativas para a prática propriamente dita, de conduta nas diferentes relações que se estabelecem em cada realidade.

É importante frisar que a liberalidade e a inversão dos valores trouxe consigo o grave problema de se confundir um importante princípio ético, isto é, o "dever fazer" com o "poder, mas não dever". Houve uma excessiva liberação dos limites, no respeito aos princípios éticos quanto ao que se refere aos "fins justificarem os meios"; ao "não roubar"; "não mentir" ou "pisar nos outros", desde que seja para atingir um objetivo definido como necessário para aquela pessoa.

Constitui esta, uma matéria de fundamental importância no mundo em que vivemos, visto estar o mesmo permeado de incertezas, inseguranças e tensões. Existe hoje, uma grande necessidade de compaixão cristã, a qual nos tempos romanos se manifestava no cuidado especial para com as viúvas, órfãos, idosos e doentes. Mais de vinte séculos depois da morte de São Lourenço, um dos primeiros mártires cristãos, defensor dos famintos e doentes, ainda se necessita de muitos Freis Damião, Irmãs Dulce e Madres Teresas de Calcutá, com o fim de cuidar da estética e da qualidade de vida dos mais desafortunados. É necessário que procuremos aprimorar o legado que estaremos deixando aos nossos descendentes e às gerações futuras.

A forma como algumas pessoas estão vivendo, as submete a frustrações e desencantos, levado-as a agirem egoisticamente e serem vingativas, submersas em esquecidas do perdão e do amor pelo próximo; perderam a noção de altruísmo, do ser gente, vivem coisificadas, praticamente, esquecidas que são filhos de Deus. Apresentam-se, muitas vezes, sem uma identidade definida, convivem concomitantemente com sentimentos antagônicos, alegria e ressentimento permeiam uma mesma pessoa. A prática do perdão a si e ao outro, capaz de promover uma harmonização no existir das pessoas praticamente inexiste. A sua auto determinação e auto confiança para o sucesso e amor está, via de regra, ausente. Vivem cercadas de perdas, desapontamentos, fracassos, solidão e silêncios; vivem mais o caráter farisaico, esquecem da verdade espiritual. Isso contextualiza uma conduta de pouca autonomia e ausência de critérios em relação aos valores culturais, sem uma conduta moral consciente, em relação aos objetivos de vida.

Acreditamos que este contexto tem contribuído para a prática da violência consigo próprio e com o ambiente. Referem Souza e Minayo (1995), que no Brasil, a violência tornou-se a segunda causa de óbito, e que parece estar resultando da deturpação dos modos de vida das pessoas, da carência de uma educação para a não ambição desenfreada, para a aceitação das próprias limitações e tolerância para com os outros. Em decorrência da decadência dos valores morais e culturais das famílias e comunidades, as pessoas esquivamse de possíveis envolvimentos que possam Ihes trazer aborrecimentos e discussões. Passaram a construir suas casas com altos muros para a própria proteção, a de sua família e mesmo, de seus bens. Existe portanto, um forte apelo a um reforço nas condutas éticas adequadas à preservação da vida. 


\section{FAMÍLIA E BEM-ESTAR}

O bem estar de cada pessoa, assim como o bem estar da comunidade, decorre da forma de vida das pessoas, a qual é influenciada pelo ambiente, no qual elas vivem e, necessariamente construída no interior de cada um desde a mais tenra idade, com a prática dos valores e conforme a origem das motivações para a prática da conduta ética. Relaciona-se fortemente aos valores praticados no ambiente onde o indivíduo se desenvolve. Implica na paz, na tranqüilidade das pessoas e até na conservação da própria vida.

A forma de viver, pensar e agir das pessoas é um legado recebido através das gerações. Esta, pode ser fortemente deturpada frente as dificuldades que as pessoas são levadas a enfrentar e como nem todos têm a devida fortaleza de caráter, poderão sucumbir às tentações vindo a deturpar o seu agir.

A conduta na qual o indivíduo estabelece sua autonomia, em concordância com suas habilidades físicas, mentais e intelectuais, decorrerá da independência e da auto-confiança, para a emissão de juízos, participação em decisões e da forma de agir, a partir da qual traçará e procurará alcançar os próprios objetivos de vida, parafraseando Nikku (1997). Esses objetivos estão diretamente relacionados ao nível de aspiração, ao que Kurtt Lewin, citado por Hersey,(1986), define como sendo o grau de dificuldade que uma pessoa deve enfrentar para atingir. É importante enfatizar que os direitos correspondem proporcionalmente às obrigações ou responsabilidades, e envolvem privilégios.

Pode-se considerar então, concordando com Chauí (1997), que os valores morais e culturais são alicerçados por conjuntos de circunstâncias de natureza ambiental, vindo dar forma e substanciar as ações dos indivíduos, sob cujas bases se estrutura a sua consciência moral e ética, a qual vai determinar a capacidade e os padrões a serem utilizados pelo indivíduo para o julgamento do valor de seus atos e de suas condutas. A qualidade dessa capacidade de julgamento é que vai definir o nível de responsabilidade desse indivíduo por suas ações, por seus sentimentos e pelas conseqüências do que faz e sente, tornando-o capaz de deliberar, decidir e escolher diante de diferentes alternativas. Neste exercício, na condição de agente consciente, conhecedor da diferença entre bem e mal, certo e errado, permitido e proibido, virtude e vício, necessitará ser capaz de avaliar, conforme suas motivações pessoais e conforme as exigências feitas pela situação, as conseqüências para si e para os outros, a conformidade entre meios e fins, a obrigação de respeitar o estabelecido ou de transgredi-lo, de julgar portanto o valor dos atos e das condutas e, de agir em conformidade com os valores morais, apto a originare incorporar uma conduta ética. A vida ética envolve necessariamente, consciência e responsabilidade, relacionada ao bem estar individual e coletivo.

\section{POR UM CONVIVER ESTÉTICO EM FAMÍLIA E COM O AMBIENTE}

A responsabilidade não é um dever imposto de fora, mas uma resposta a um pedido que interessa ao indivíduo. Para a aquisição da responsabilidade, certos elementos básicos podem estar intimamente implicados, os quais estão na capacidade de amar do indivíduo, referidos por F romm (1983), como, desvelo, responsabilidade, respeito e conhecimento. A afirmação da própria vida, felicidade, crescimento, liberdade do indivíduo, originase do amor. 0 indivíduo só amará a si mesmo, se for capaz de amar ao outro.

O ser humano compreende o mundo, intelectual e emocionalmente, através do amor e através da razão. Seu poder de amar habilita-o a romper a muralha que o separa de outra pessoa e a compreender essa. 0 amor e a razão são duas formas diferentes de compreender o mundo e nenhuma delas pode existir sem a outra. São manifestações de poderes diferentes, o da emoção e o do pensamento, no entanto convivem em relação íntima e inseparável. 0 amor é a forma produtiva do relacionamento, com outros e consigo mesmo uma vez que decorre dele o desejo de ver a outra pessoa crescer e desenvolver-se. 0 amor e a compreensão de próprio eu, não podem ser separados do respeito e da compreensão a outro indivíduo. 0 amor do próprio eu está inseparavelmente ligado ao amor a qualquer outro eu.

O conceito sociedade/ambiente, é tratado em relação ao indivíduo. É grande a importância de ter-se metas, objetivos de vida. É fundamental instrumentalizar-se para orientar motivos a serem utilizados como alvo para 0 atingimento de metas, aos quais podem decorrer de diversos fatores, seja a situação econômico-financeira, ou outra. Tais fatores, entretanto, influenciam esta questão somente muito indiretamente, visto que objetivos podem ser ensinados à criança, simplesmente a partir de idéias simples e criativas, como sejam, procurar, 
mesmo sendo ético, ser o melhor em uma brincadeira, em uma gincana, tirar uma nota em um escore x ou y, ou ainda aperfeiçoar-se em uma tarefa doméstica. Todas essas coisas podem sofrer influência do ambiente, porém não estão inteiramente sob nossa dependência.

É necessário que estabeleçamos uma reflexão sobre como estamos lidando com o legado recebido de nossos antepassados, se temos procurado aperfeiçoar, dignamente, aquilo que recebemos dos que nos antecederam. E como estamos procurando preparar um percurso mais humano, neste mundo, para deixar aos que vierem após nós, uma herança mais digna, de forma que eles tenham do que se orgulharem de nós, ao invés de arrependerem-se de terem sido escolhidos a nos substituir no mundo.

Importante se faz que as pessoas revejam seus valores, e reflitam sobre o viver em harmonia com os outros e com o ambiente, voltando a atenção para um trabalho mais direcionado para a auto-estima, que é um fator fundamental para o desenvolvimento mais autêntico da personalidade, na construção de desejos, sonhos e ideais saudáveis, tendo em vista o cuidado estético de si próprio e do ambiente. Esta ação, compete essencialmente à família, visto que, mesmo devendo ser incentivada ao longo de toda a vida, merece prioridade na infância, quando a criança está formando seu quadro de referência, que levará para o resto da vida, do qual poderá depender todo o seu sucesso pela vida à frente, (Guedes, $\left.S^{\text {inho }}, 2000\right)$.

\section{O PAPEL DA FAMÍLIA NA FORMAÇÃO DE UMA CONDUTA ALTRUÍSTA}

Um dos fatores de fundamental importância, é o apoio da família no que se relaciona a construção da consciência voltada para a firmeza de caráter e para o altruísmo, assim como no que se refere ao desenvolvimento da competência, da espiritualidade, da prática do amor e do perdão, o afastamento de mágoas e de ressentimentos, que podem afastar e amedrontar as pessoas entre si. Integrar, de forma organizada aos padrões culturais percepção, sentimento e pensamento; orientando o desenvolvimento da concepção permanente sobre o que é certo e o que é errado. Ajustando-se no indivíduo de forma íntima e harmoniosa, podendo contribuir para seus posicionamentos político-sociais e, em maior empenho, no combate aos vários tipos de comportamentos inadequados.

Fundamental também é trabalhar tendo em vista a afirmação da autonomia, que significa a instância na qual o indivíduo estabelece sua própria forma de conduta, sobre tudo aquilo que se diz ou se faz; implica no domínio das habilidades físicas, mentais e intelectuais para tomar decisões e agir conforme as mesmas. Decorre daí a independência e a auto-confiança, e a capacidade de emitir juízos, determinar e procurar alcançar as próprias metas. A cada direito (que decorre do nível de autonomia), corresponde uma obrigação ou responsabilidade, implica na capacidade de responder pelos próprios atos e tomar decisões. Está sempre em conexão com a autoridade relativa, às obrigações que competem a alguém imbuído dessa determinada autoridade, ou encarregado do cumprimento de determinada tarefa, envolvendo direitos e privilégios.

O capítulo das motivações é um aspecto importante de ser considerado no ajustamento familiar e social. Essas, incidem, em geral sobre 0 atendimento das necessidades e dos desejos. A não consecução de um desejo se reverte em frustração, que é o impedimento da obtenção do objetivo, ou oposição a essa obtenção. A frustração poderá, ao mesmo tempo, funcionar tanto como uma alavanca que força a aprendizagem de um novo comportamento, como se transformar simplesmente, em rancor e raiva, reações extremamente indesejáveis para a construção de relacionamentos saudáveis.

A fim de que a pessoa sinta-se prazeroso e confortável, é necessário preservar o seu estado de satisfação ou prazer, uma vez que esse fornece a motivação e a energia para uma abordagem criativa da vida. R elacionase diretamente ao autoconceito, o qual se refere a uma autopercepção global, e relativamente constante do indivíduo, e que só muda gradualmente. É importante estar associada a uma harmonia entre o estado interno e a situação externa, ou seja aquela que se lhe apresenta no ambiente.

Já o sentimento de vergonha e de culpa, tem um efeito desintegrador na personalidade. Tanto a vergonha como a culpa, constituem uma barreira para a auto-aceitação, embotam a espontaneidade, que é a essência do prazer, coloca o ego contra o corpo destruindo a unidade da personalidade. Produz um conflito que afasta a saúde emocional e consequentemente $o$ rendimento da pessoa. A humilhação mancha a personalidade, e vergonha e humilhação andam de mãos dadas. Ambas anulam a dignidade do indivíduo, seu auto-respeito e seu sentimento de que é igual aos outros (tão bom quanto eles). Toda pessoa que carece de sentimento de 
dignidade e que se percebe inadaptada sente-se envergonhada ou humilhada, o que pode ser consciente ou inconsciente. A conduta é ditada pelos sentimentos, tanto conscientes como inconscientes (que são as raízes das dificuldades de adaptação). Vale destacar que, as emoções, cujo convívio nos provocaria muito sofrimento vão para o inconsciente, assim é que, quanto maior a repressão social e quanto menor a força de uma pessoa para suportar tensões internas, maior será o conteúdo do seu inconsciente, (Pikunas, 1981).

A competência, a independência e a criatividade estão, necessariamente, na dependência da autoestima, a qual em sua estruturação imprescinde, segundo P ikunas (1981), de aceitação total ou quase total, por si e pelos outros; de estabelecimento de limites disciplinares claramente definidos e negociados, e de respeito e amplitude para a ação do indivíduo.

O inverso da auto-estima é o ódio a si mesmo, decorre da pessoa encontrar em si mesmo muitos aspectos indesejáveis, sejam seus defeitos, sua covardia, seus pecados, a não concretização de seus objetivos. Gera o desejo de destruir e de ferir. A pessoa se humilha, se pune, mental e fisicamente, podendo chegar a atentar contra a própria vida. É uma situação ocasionada por sentimentos de culpa, pela repressão de emoções e por vergonha; a pessoa é condicionada a uma reação depressiva.

Trabalhar a auto-estima do indivíduo, é portanto fator fundamental para o desenvolvimento saudável da personalidade, no sentido do atendimento dos desejos, dos sonhos e dos ideais.

\section{O SENTIDO DA ESTÉTICA FAMILIAR VOLTADO PARA A FELICIDADE}

O exercício de uma convivência saudável demanda inteligência, para agir com previsão ou comportarse eficientemente. Caracteriza a pessoa capaz de enfrentar e solucionar novos problemas e de se ver a si mesma como capaz de resolver ambigüidades em novas situações, (Pittenger,1977). A prática dessa convivência demanda a aplicação de uma regra básica, o recomeçar da conquista a cada dia, procurar, a cada dia, descobrir a melhor maneira de estimular, valorizando o outro e valorizando-se.

É necessário ter a consciência de que é possível conviver com o outro, sem necessariamente perscrutálo em tudo, mas simplesmente aceitá-lo em função do crescimento que há de ter, e das dificuldades que terá para enfrentar e vencer, no mundo que o rodeia, onde vive e terá que continuar vivendo. Com a consciência, de que todas as relações são transitórias, devendo portanto se preparar para as separações que acontecerão fatalmente, a fim de que possa encarar com resignação, sem que venha a constituir uma tragédia.

S egundo Lewin citado por Hersey (1986), o comportamento está sujeito às influências das percepções, sentimentos e pensamentos do indivíduo. Se revela na interação do indivíduo com seu meio ambiente e individualiza a maneira de ser, de pensar e de agir de cada pessoa. 0 comportamento do indivíduo resulta não apenas das forças da personalidade, mas também de uma interação dele com o meio externo, no que estão envolvidas características psicológicas e sua forma própria de organização. A própria organização dos traços psicológicos de um indivíduo se evidenciam com maior relevância em algumas situações do que em outras, e também pode ser modificada á medida que o indivíduo interage com o meio. A personalidade pode ser influenciada, tanto por fatores externos quanto internos.

A felicidade é o critério de excelência na arte de viver, e de virtude na acepção que esta tem na ética humanista. É muitas vezes considerada como o antônimo lógico de tristeza e dor; é acompanhada de um aumento de vitalidade, intensidade de sentimentos e pensamentos, e produtividade; é o indício de que o homem encontrou a solução para o problema de sua existência: a realização positiva de suas potencialidades. Já a infelicidade por sua vez, caracteriza-se por um decréscimo dessas capacidades e funções.

\section{FAMÍLIA, ENQUANTO SER QUE EDUCA PARA O VIVER NO MUNDO}

E ducar, constitui um processo flexível, dinâmico, complexo, social, histórico e reflexivo, que se constrói a partir da relação pessoa-a-pessoa, na qual quem ensina aprende e quem aprende ensina. Demanda, uma contínua troca de conhecimentos e experiências mútuas, uma vez que cada ser que interage, o faz com suas idéias, valores, atitudes e experiências. É um processo estético, ético e criativo, que possibilita ao ser humano, o desenvolvimento das próprias potencialidades, tendo em vista a aquisição de autonomia quanto as próprias ações, tornando-se sujeito das situações vivenciadas. Facilita o enfrentamento de situações de estresse e 
crise, favorecendo o viver de forma saudável. Os que participam da experiência crescem pessoalmente e transformam a si e ao meio em que estão inseridos. É um processo que exige disponibilidade, respeito, afetividade, confiança, alegria, sensibilidade, capacidade de ouvir, compromisso e responsabilidade. Toda educação envolve o compartilhar pensamentos sobre um universo em mudança, e em que fins e meios se inter-relacionam dinamicamente.

O sucesso na experiência de educar é sempre reforçado pelos valores éticos e espirituais, isto é, a forma como esta é percebida ou entendida influenciam o processo de interação.

A família deve apoiar suas ações em códigos ou critérios, que poderão contribuir oferecendo opções de incentivos para a formação de atitudes. Esses critérios referem-se a princípios que visam transmitir crenças e comportamentos, e estimular o posicionamento relativo a questões éticas e morais, no que se inclui, seus direitos de participação nas decisões que influenciam a vida, a saúde e os serviços comunitários.

É fundamental, desenvolver na pessoa a habilidade para estabelecer metas e de descobrir estratégias para atingi-las. Para o quê, é necessário que haja a atitude do reconhecimento do motivo, o comportamento, 0 treino em descobrir e entender os próprios motivos. 0 que indispensa o auto-conhecimento, a naturalidade e espontaneidade do viver vivido, a fim de que os motivos tenham pertinência com o ser que está aí, e segue rumo aquelas metas que thes foram inspiradas segundo os próprios motivos. S eja, no trabalho ou no estudo, formular sempre, além do propósito, um plano e segui-lo como se alguém o houvesse imposto, como uma obrigação. Se este for continuamente interrompido ou alterado, a pessoa estará debilitando sua vontade e perderá o apoio das próprias decisões.

Lembrar de premiar sempre mais do que punir e evitar reprimendas; o simples elogio a uma pequena ação do cotidiano já pode representar um estímulo considerável para preservar ou elevar a auto-estima, tendo em vista, incentivar bons hábitos de cidadania.

Faz-se necessário desenvolver-se na prática de ensinar aprendendo, a partir de uma intenção deliberada, tendo em vista a solidariedade, a esperança, procurando afastar a angústia e o medo, conversando e dividindo tudo o que tem de si mesmo (Gadotti, 1989). Pode-se partir de um treinamento pessoal para a afeição pura e simples, manifestada no olhar, em um sorriso, escondida em um carinho, bem própria de um ente querido. É preciso treinar a si mesmo e ao outro para que cada encontro seja amoroso, educativo e humano, valorizando sempre os mínimos gestos, os mínimos desejos, cada olhar. Ninguém se empobrece dando, e não é preciso sair de si mesmo para se dar. Vale lembrar que amor e disciplina não se excluem, ao contrário, completam-se. A doação resulta, de algum modo, diretamente em prazer, que tem sua essência na sensação do alívio da tensão dolorosa. Somente o ser que se sente completo, ama verdadeiramente, e é capaz de fazer, agir e criar.

Podem integrar esse rol de princípios: o orientar quanto a crença na capacidade de realizar, de se adaptar a mudanças; pensar sempre em ter sucesso na vida, aproveitando, ao máximo, as próprias aptidões, com a mente voltada para ideais justos e nobres; o estabelecimento de um esquema de incentivos e elogios, de forma que ajude a desenvolver a auto-estima, tendo fé no que faz e em procurar fazer sempre o melhor possível; estimular a ter sempre, uma atitude positiva em relação ao mundo; promover o entendimento de que a verdade é sempre vista como uma regra de ouro, mas que se deve evitar, entretanto, desmoralizar alguém usando por motivo o valor da verdade; perscrutar a preciosa oportunidade de crescimento pessoal, a partir das falhas apresentadas no próprio comportamento ou no do outro; mostrar que o enfrentamento dos próprios padrões poderá conduzir a um melhor entendimento sobre os próprios conhecimentos, e a uma possível transformação sobre o "que é", e o que "deve ser"; estimular o pensamento voltado para o rejuvenescimento e para o próprio progresso.

\section{CONSIDERAÇÕES FINAIS}

Conforme o exposto neste trabalho, é importante destacar que o ser humano deve nortear 0 alvo de seu viver na felicidade, que é acompanhada de um aumento de vitalidade, produtividade, intensidade de sentimentos e pensamentos, enquanto que a infelicidade, traz consigo um decréscimo dessas capacidades e funções. Tem sua atividade produtiva inevitavelmente acompanhada de prazer, representado pela satisfação de alivio da tensão dolorosa, cujas intensidade e duração, são proporcionais. 
É fundamental que a pessoa seja vista sob uma perspectiva holística, que a orientação seja direcionada no sentido de um ser unificado, tal como um sistema vivo, em constante interação com seu ambiente, trocando informações, matéria e energia entre seu próprio sistema e o ambiente. Como por exemplo a célula que precisa extrair as substâncias de que necessita para sobreviver, de seu mundo exterior. Dentro de si, ela deve manter ordem em seu imenso mundo de moléculas. É um ser consciente, racional, perceptivo, controlador, intencional, voltado à ação e voltado ao tempo.

O estímulo tem um papel preponderante na formação do indivíduo, a partir do que ele poderá fazer o melhor uso de suas capacidades e realizar sua auto-estima; uma vez que possui potencial único e esforça-se no sentido da auto-direção e da independência relativa; deseja não apenas fazer o melhor uso de suas capacidades e potencialidades, mas também cumprir suas responsabilidades. A autoconcientização e a autoaceitação, são fundamentais ao senso de integridade e auto-estima do indivíduo. 0 que quer que $o$ indivíduo faça, representa seu melhor juízo no momento.

Ser responsável pela vida de uma pessoa significa relacionar-se com a sua essência humana. Amar produtivamente, implica cuidar e sentir; visa, não a satisfação, mas o ser, não se coaduna com passividade nem com a atitude de mero observador, face à vida daquela pessoa. Implica esforço, cuidado e responsabilidade por seu desenvolvimento (F romm, 1983), a fim de tornar-se apto a lidar com as dificuldades da vida. 0 amor conduz a um estado de paz, de harmonia e de serenidade.

ABSTRACT: The present work emphasizes ethical and moral conduct aspects which permeate families' and its members' social space. It approaches subjects and principles that need to be worked in family, as focusing a healthy living together, to improve personal satisfaction level, which in fact, can contribute to the reduction of self violence events and violence with the others who share the space "mundus vivendi "at familiar and social atmosphere.

KEY WORDS: Family; Ethics; Esthetcs.

RESUMEN: El presente trabajo enfatiza los aspectos de la conducta ética y moral que permeiam el espacio social de las famílias y de sus miembros. Aborda las questiones y principios que son precisio de serem trabajados en família, tiendo en vista un convivir saudable, mejorando el nivel de satisfación pessoal, lo que inclusible podrá contribuir para reducir los evientos del violencia propria y con los demais que compartilhan el espacio "mundus vivendi" en el ambiente familiar y social.

PALABRAS CLAVE: Família; É tica; Estetica.

\section{REFERÊNCIAS}

1 BOEMER, M. R.; SAMPAIO, M. A. O exercício da enfermagem em sua dimensão bioética. Rev, latino-am, enfermagem. Ribeirão P reto, v. 5, n.2, p. 33-38, abril, 1997.

2 CHAUI, M. Convite à filosofia, 8. ed. São Paulo: Ática. 1997.

3 Cohen, C.; Ferraz, F. C. Direitos humanos ou ética das relações. In: SECRE, M.; COHEN, C. Bioética. São Paulo: E dusp, 1995, p. 37-49.

4 COLLET, N.; ROZENDO, C. A.; Palvelqueires, S. Algumas reflexões sobre um tema polêmico: a ética na enfermagem. Rev. Gaúcha Enferm., Porto Alegre, v.16, n.1/2, p.82-87, jan/dez.1995.

5 FROMM. E. Análise do homem.13. ed. Rio de J aneiro: Zahar, 1983.

6 GADOTTI, M. Dialética do amor paterno. 5. ed. São Paulo: Cortez, 1989. 111p.

7 GUEDES SOBRINHO, E. H. Como trabalhar a auto-estima dos alunos. 2000. Digitado.

8 HERSEY, P.; BLANCHARD, K. H. Psicologia para administradores: a teoria e as técnicas da liderança situacional. Trad. Edwino A. R oyer. São Paulo: Editora Pedagógica e Universitária. 1986.

9 JANKÉ LÉ VITCH, O paradoxo da moral. Campinas: Papirus, 1991.

Fam. Saúde Desenv., Curitiba, v.3, n.1, p.26-34, jan.jun. 2001 
10 LUNARDI, V. L. Responsabilidade profissional da enfermeira. Texto contexto Enferm., Florianópolis, v. 3, n. 2, p. 47-57, jul./dez. 1994.

11 NIKKU, N. Informative paternalism: studies in the ethics of promoting and predicting health.S weden: Linköpings Universitet. 1997. 368p.

12 NOUWEN, H.J.M. A volta do filho pródigo. São Paulo: Paulinas. 1997.

13 PIKUNAS, J. Desenvolvimento humano - uma ciência emergente. São Paulo: McG raw- Hill. 1979.

14 PITTEngER, O. E. Teorias da Aprendizagem na prática educacional. São Paulo: EPU-EDUSP. 1977

15 Rodrigues, M. S. P.; Guedes Sobrinho, E. H; Silva, R. M. da. A família e sua importância na formação do cidadão. Fam. Saúde Desenv., Curitiba, v.1, n.1, jul./dez. 2000.

16 Souza, E. R.; Minayo, M. C. S. O impacto da violência social na saúde pública do Brasil: década de 80. In: MINAYO, M.C. Sousa. Os muitos Brasis, saúde e população na década de 80. São Paulo: HUCITEC-ABRASC0, 1995. 